\title{
(C) OPEN ACCESS \\ Views of UK doctors in training on the timing of choosing a clinical specialty: quantitative and qualitative analysis of surveys 3 years after graduation
}

\author{
Shelly Lachish, Michael J Goldacre, Trevor William Lambert
}

\begin{abstract}
- Additional material is published online only. To view please visit the journal online (http://dx.doi.org/10.1136/ postgradmedj-2017-135460).

UK Medical Careers Research Group, Unit of Health-Care Epidemiology, Nuffield Department of Population Health, University of Oxford, Oxford, UK
\end{abstract}

Correspondence to Trevor William Lambert, UK Medical Careers Research Group, Unit of Health-Care Epidemiology, Nuffield Department of Population Health, University of Oxford, Oxford OX3 7LF, UK; trevor.lambert@dph.ox.ac.uk

Received 17 November 2017 Revised 10 August 2018 Accepted 27 October 2018 Published Online First 6 December 2018

\begin{abstract}
Background Workforce studies show a declining proportion of UK junior doctors proceeding directly to specialist training, with many taking career breaks. Doctors may be choosing to delay this important career decision.
\end{abstract}

Aim To assess doctors' views on the timing of choosing a clinical specialty.

Methods Surveys of two cohorts of UK-trained doctors 3 years after qualification, in 2011 and 2015.

Results Presented with the statement 'I had to choose my career specialty too soon after qualification', $61 \%$ agreed (27\% strongly) and $22 \%$ disagreed (3\% strongly disagreed). Doctors least certain about their choice of specialty were most likely to agree (81\%), compared with those who were more confident $(72 \%)$ or were definite regarding their choice of long-term specialty (54\%). Doctors not in higher specialist training were more likely to agree with this statement than those who were ( $72 \%$ vs $59 \%$ ). Graduate medical school entrants (ie, those who had completed prior degrees) were less likely to agree than non-graduates ( $56 \%$ vs $62 \%$ ). Qualitative analysis of free text comments identified three themes as reasons why doctors felt rushed into choosing their future career: insufficient exposure to a wide range of specialties; a desire for a greater breadth of experience of medicine in general; and inadequate career advice.

Conclusions Most UK-trained doctors feel rushed into choosing their long-term career specialty. Doctors find this difficult because they lack sufficient medical experience and adequate career advice to make sound choices. Workforce trainers and planners should enable greater flexibility in training pathways and should further improve existing career guidance.

\section{INTRODUCTION}

Understanding the determinants of medical career paths and the decision-making processes of doctors in training is of critical importance to health service providers, government agencies, policy makers and medical educators and trainers. Doctors' career decisions are a crucial factor in determining the long-term structure and composition of the health workforce and strongly influence doctors' job satisfaction and enjoyment. ${ }^{12}$ There is, thus, considerable interest in identifying factors that facilitate effective career decision-making in medicine. This is particularly relevant given the current discordance between the distribution of medical practitioners across specialties and the future health needs of an ageing population. ${ }^{34}$

In the UK, medical graduates undertake 2 years of core medical training known as the Foundation Programme prior to being admitted to specialist training. The programme is a workplace-based training programme, typically consisting of six 4-month rotations in different specialties. ${ }^{5}$ The transition to specialist training after 2 years was designed as part of the Modernising Medical Careers (MMC) initiative in 2005 to help doctors progress more quickly to their desired careers by reducing time spent in unnecessary or inappropriate training. ${ }^{6}$ Prior to MMC, doctors could take several years after graduation to decide on their future specialty. Currently, foundation doctors are expected to apply for their choice of long-term specialty career in November of their second year of foundation training, just 16 months after graduation. ${ }^{5}$ Foundation doctors may choose not to proceed directly to specialty training, deciding instead to work in non-training posts or to take a career break (for personal or vocational reasons). Neither of these options counts as accrued experience, however, and thus delay the completion of medical training. ${ }^{57}$

In recent years, the proportion of Foundation Year 2 (F2) doctors proceeding directly to specialist training has declined from $71 \%$ in 2011 to just 50\% in 2016. This contributes to difficulties in workforce planning in the long term, since the numbers who complete training falls, and in the short term adds to medical staffing shortages, since doctors in training in the UK provide much of the resource to meet service demand. ${ }^{8}$ Although the reasons for this decline have not been explored in detail, reports show that doctors taking a 'career break' constitute the largest category within this group. ${ }^{8}$ This suggests that many foundation doctors are choosing to delay the timing of their decision regarding choice of long-term specialty.

There has been a drive to increase recruitment in certain shortage specialties, including general practice, emergency medicine, general medicine, radiology, pathology and psychiatry.

One means of assessing whether doctors feel rushed to choose their career specialty is to seek the views of doctors who have recently completed foundation training regarding the timing of this career decision. Here, we report the views of over 
5000 UK-trained doctors about whether they considered that they had to choose their long-term career specialty too soon after qualification.

\section{METHODS}

The UK Medical Careers Research Group undertakes multipurpose surveys of career intentions and progression from selected graduating cohorts from all medical schools in the UK. Surveys encompass questions designed to elicit the views of respondents about their experiences of training and working in UK medicine (see detailed methods). ${ }^{9}{ }^{10}$ Here, we report on the results of surveys, in respect of the timing of expected career specialty choice decisions, sent to the UK medical graduates of 2008 and 20123 years after qualification in 2011 and in 2015, respectively.

Doctors were asked to state if they were employed in a specialist training post or equivalent within the National Health Service (NHS) or not (ie, working or training in medicine outside the UK, seeking employment or not working in medicine). They were then asked to list up to three choices of long-term career specialty, in order of preference, and to state how certain they were that their stated preferred specialty was their choice of long-term career ('definite', 'probable' or 'uncertain'). The doctors were then asked to respond to the following statement: 'I had to make my career choice of specialty too soon after qualification' by indicating their degree of agreement on a 5-point scale (from 'strongly agree' to 'strongly disagree').

We assessed variation in responses between the two surveys using a non-parametric Kruskal Wallis test. For subsequent analyses, we created binary dependent variables from the 5-point scale responses by combining respondents who agreed or strongly agreed as one group (which we refer to as 'Agreed') and combining all other responses as a second group (neither agree nor disagree, disagree, strongly disagree). We then used $\chi^{2}$ tests to examine how responses varied according to how certain doctors were about their choice ('definite', 'probable' or 'uncertain') and (1) between doctors who were or were not in specialist training, (2) between doctors who were graduate entrants to medical school (ie, those who had completed other degrees prior to medical school) or not and (3) between men and women. We use a Bonferroni correction to adjust for multiple testing $(\mathrm{p}=0.004)$.

At the end of our survey doctors were invited to provide free text comments ('Please give us any comments you wish to make, on any aspect of your training or work'). To augment our quantitative analyses and provide context in which to better interpret our results, we searched the free-text comments made by respondents for those that included the words 'timing', 'too soon', 'too early', 'rush"'. We filtered this list to keep only those comments in which these key words were used to discuss the timing of career decision making. We used this final set of comments to identify broad themes reflecting the reasons and motivations behind the doctors' responses to our main question. We tabulate these themes and present them along with selected illustrative quotes. We examined the comments made by doctors which were not included in the final set, and we found no comments about career choice timing: this gave us confidence that we did not miss relevant comments. The doctors' identities were protected by redaction and their gender and chosen specialty are shown next to each quote, where known.

\section{RESULTS}

\section{Response rate}

Excluding medical graduates who were deceased, declined to participate or were untraceable, the overall response rate was

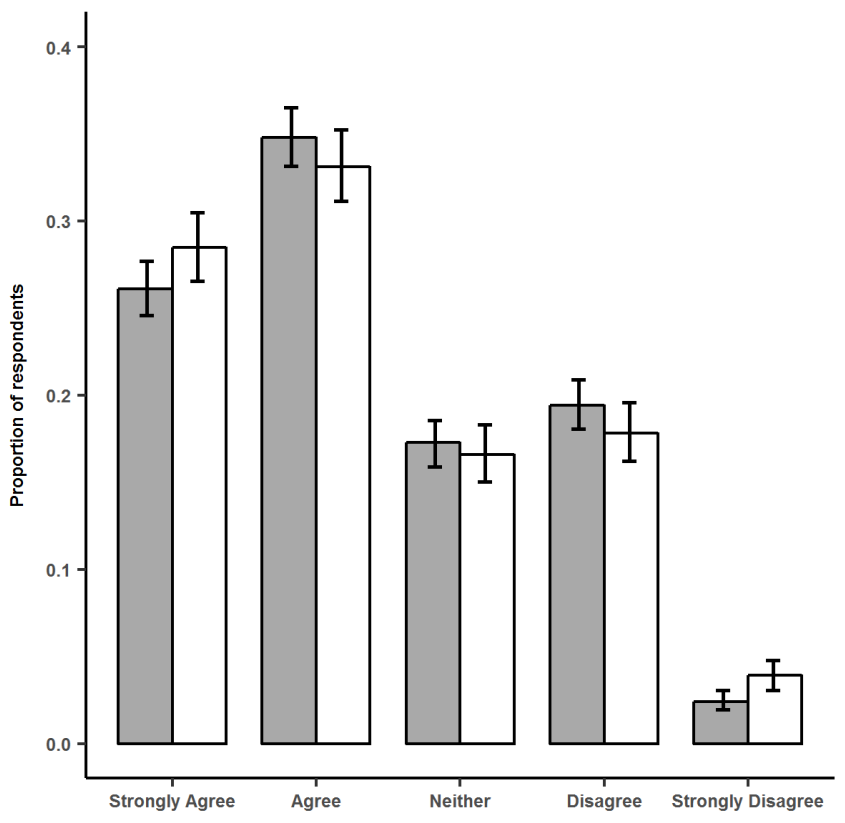

Figure 1 Percentages of doctors of two cohorts surveyed 3 years postqualification (2011 grey bars; 2015 white bars) responding to the statement 'I had to make my career choice of specialty too soon after qualification', on a five-point scale from 'strongly agree' to 'strongly disagree'. Error bars are $95 \% \mathrm{Cl}$.

$48.2 \%(3390 / 6540)$ for the 2011 survey and $41.9 \%(2063 / 4921)$ for the 2015 survey. The response rate among women was $47.4 \%$ $(n=3244)$ and among men was $42.7 \%(n=1969)$.

\section{Timing of selection of long-term career specialty}

In response to the statement 'I had to choose my career specialty too soon after qualification', 61\% agreed (27\% strongly) and $22 \%$ disagreed (3\% strongly disagreed; figure 1 ). There was no statistical difference between the two surveys in the pattern of responses to this statement $(p=0.29)$. Doctors who were not employed in higher specialist training at the time of our survey were significantly more likely to agree with this statement than those who were $72 \%$ vs $59 \%: \chi^{2}=49.48, \mathrm{df}=1, \mathrm{p}<0.001$; table 1A). This was true for both surveys (2011: $72.3 \%$ vs

Table 1 Percentage of doctors who 'agreed' (either agreed or strongly agreed) with the statement: 'I had to make my career choice of specialty too soon after qualification' as a function of whether they were (A) employed in specialist training or not, $(B)$ graduate entrants to medical school or not or $(C)$ their gender

\begin{tabular}{|c|c|c|}
\hline Characteristic & $\%$ Agreed & $n / N$ \\
\hline \multicolumn{3}{|c|}{ (A) In specialist training } \\
\hline Yes & 58.9 & $2474 / 4202$ \\
\hline No & 72.3 & $630 / 880$ \\
\hline \multicolumn{3}{|c|}{ (B) Graduate status } \\
\hline Graduate & 55.5 & $455 / 820$ \\
\hline Non-graduate & 62.2 & $2686 / 4318$ \\
\hline \multicolumn{3}{|l|}{ (C) Gender } \\
\hline Men & 61.3 & $1193 / 1947$ \\
\hline Women & 61.1 & $1960 / 3207$ \\
\hline
\end{tabular}

Sample sizes are given in brackets and values in bold indicate significant differences between the categories of comparison $(p<0.001)$. 


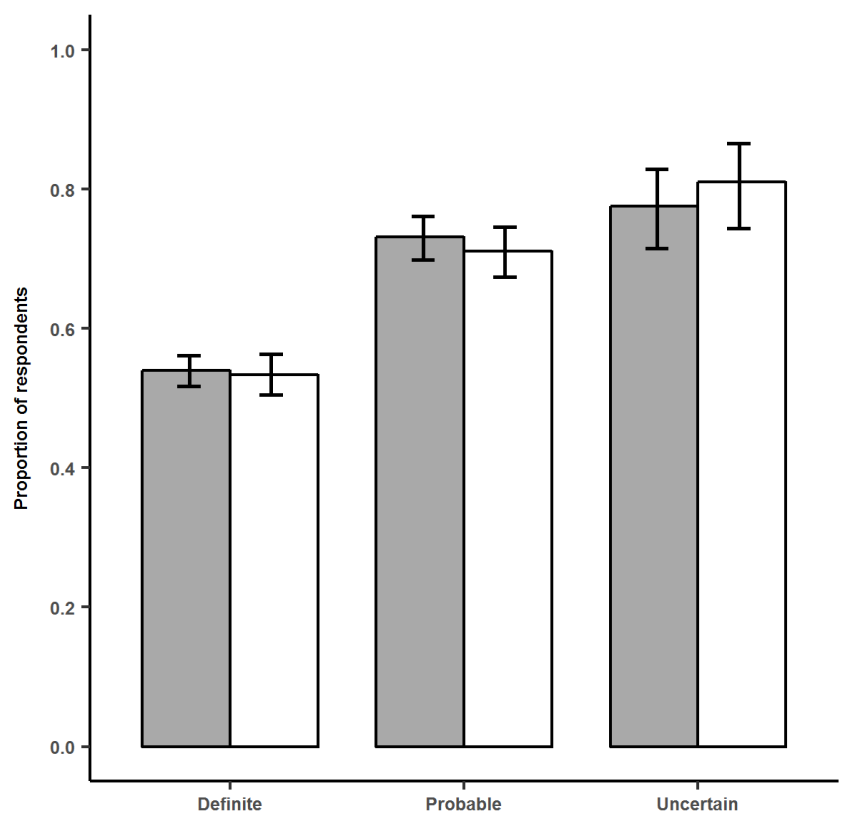

Figure 2 Percentages of doctors who 'agreed' (either agree or strongly agree) with the statement 'I had to make my career choice of specialty too soon after qualification' as a function of their degree of certainty regarding their choice of long-term specialty. Grey bars depict responses to the 2011 survey, white bars to the 2015 survey. Error bars are $95 \% \mathrm{Cl}$.

$58.9 \% ; \chi^{2}=27.11, \mathrm{df}=1, \mathrm{p}<0.001 ; 2015: 71 \%$ vs $59 \%$; $\left.\chi^{2}=22.03, \mathrm{df}=1, \mathrm{p}<0.001\right)$. A higher proportion of respondents to the 2015 survey were not working as specialist trainees (23\%) compared with the 2011 survey (13\%; online supplementary table 1), reflecting the UK-wide increase in doctors delaying their entrance to specialist training. ${ }^{8}$

We found that the degree to which doctors agreed with the statement varied with how certain they were about their specialty choice (2011 survey: $\chi^{2}=117.32, \mathrm{df}=2, \mathrm{p}<0.001 ; 2015$ survey: $\chi^{2}=85.49, \mathrm{df}=2, \mathrm{p}<0.001$; figure 2 ). Around $80 \%$ of doctors who reported feeling uncertain regarding their choice of longterm specialty agreed that they had had to make their decision too soon after qualification (figure 2). Even among doctors who were definite that their specialty choice would be their longterm career specialty, more than half still reported feeling rushed to make their decision (54\% 'Agreed'; figure 2). Doctors who were graduate entrants to medical school were less likely than non-graduates to agree that they had to choose their career specialty too soon after qualification $56 \%$ vs $62 \%$ : $\chi^{2}=13.09$, $\mathrm{df}=1, \mathrm{p}<0.001, \mathrm{p}=0.010$; table $1 \mathrm{~B})$. Men and women did not differ in the degree to which they agreed with the statement (61\%: $\chi^{2}=0.13, \mathrm{df}=1, \mathrm{p}=0.910$; table $\left.1 \mathrm{C}\right)$. There were no statistically significant differences between the two surveys for these latter categorical comparisons $(p>0.1)$.

\section{Analysis of free text comments}

Our search of the free text comments provided by survey respondents identified 147 comments that contained our search terms in relation to the timing of career decision making. Based on the information contained within these comments, we identified three themes depicting reasons why doctors felt rushed into choosing their future career: (1) insufficient exposure to specialties during the Foundation Programme, (2) a desire for a greater breadth of experience of medicine than is offered during the Foundation Programme, and (3) inadequate career advice (table 2). The first and second themes were most often cited (65 and 63 times, respectively) and were cited together 22 times (table 2). Of the 147 comments, 44 comments cited more than one theme, while 18 comments did not cite any. Only 3 of the 147 comments contained positive remarks regarding the timing of career decisions.

\section{DISCUSSION}

The results of this study show that over half of the responding UK-trained doctors felt rushed into choosing their long-term career specialty. Moreover, doctors who were least sure about the specialty choice they had made were most likely to report feeling rushed into making that choice. Importantly, we showed that these patterns were stronger among doctors who were not employed in specialist training positions within the NHS. This suggests that the pressure to choose a career specialty too early may have repercussions for career progressions and trajectories, as those who are least confident are less likely to make an effective choice and may simply 'choose not to choose'.

Choosing which medical discipline to specialise in is perhaps the most important postgraduate career decision a doctor will ever make, both for his or her well-being and to ensure optimal outcomes for the health service. Indeed, national health agencies invest considerable resources to understand how doctors make career decisions and how to facilitate effective career decision making for doctors. ${ }^{811} 12$ Our findings provide a strong indication that the current circumstances under which UK-trained doctors are required to make their career choice are suboptimal. Through exploration of the qualitative comments of a subsample of our survey respondents, we elucidated possible reasons for these qualitative findings. First, doctors told us that career choice is hampered by insufficient exposure to a variety of clinical specialties during the Foundation Programme itself. The Foundation Programme for UK-trained doctors was designed to provide doctors with the opportunity to develop experience in a wide range of specialties, although briefly via 4 -month rotations. ${ }^{5}$ In reality, however, the degree of choice in rotations is limited by several factors: logistics (not least that the deadline for specialty training applications occurs after just four of the six rotations); the quality of the doctor's application; other doctors' preferences and the popularity of different specialities. ${ }^{13}$ Many doctors commented that this situation was problematic.

Second, doctors wish to experience a greater breadth of medicine before specialising than is possible under the rigid training structure of the Foundation Programme. The Foundation Programme was designed to help facilitate rapid progression through training stages by reducing time spent in unnecessary or inappropriate training. ${ }^{8}$ However, it seems that this streamlining of medical training may have come at a cost: it may limit the breadth of medical experience and expertise doctors can gain prior to embarking on specialist training. This suggestion is supported by our finding that doctors who were graduate entrants to medical school were less likely to feel that they had to make their choice of career specialty too soon after graduation. Graduate entrants to medical school are on average older than other doctors and have completed a degree prior to entering medical school. Hence, they may possess a broader set of personal and vocational experiences on which to base their career choice decisions. Career development theories recognise the importance of self-concept (or how we see ourselves) to the decision-making process and acknowledge that it takes time to develop. ${ }^{14}$ Making career choices before this occurs 
Table 2 Themes depicting reasons why doctors feel rushed into making career choices, identified from free text comments provided by respondents, along with indicative quotes illustrating each theme, and the number of times each theme appeared

\begin{tabular}{|c|c|c|}
\hline Themes & Indicative quotes & $N^{*}$ \\
\hline $\begin{array}{l}\text { Career choice is hampered by } \\
\text { minimal exposure to specialties } \\
\text { during the Foundation } \\
\text { Programme }\end{array}$ & $\begin{array}{l}\text { 'I feel that we have to make career decisions too early on in our career, I would have appreciated more time to experience other } \\
\text { specialties.' [Female; Anaesthetics] } \\
\text { 'I feel currently that Specialist training after Medical School/Foundation Year is very concentrated to becoming a Consultant as soon as } \\
\text { possible. There are not many options to experience different specialities before you are expected to apply only about a third of the way } \\
\text { through FY2 year which I personally think was too soon for myself who was not entirely sure where I wanted to go.' [Female; General } \\
\text { medicine, LAT Registrar] } \\
\text { 'I feel choosing specialty, and effectively the career path for the rest of your life, in October/November of F2 is too early. For me, I was } \\
\text { trying to choose between GP and paediatrics, which I only rotated through in the second half of F2, after the application deadline. I } \\
\text { therefore took a year out to ensure I experienced working in these specialties before making my decision.' [Male; Paediatrics] }\end{array}$ & 65 \\
\hline $\begin{array}{l}\text { Doctors desire a greater } \\
\text { breadth of experience than that } \\
\text { available through the Foundation } \\
\text { Programme }\end{array}$ & $\begin{array}{l}\text { 'I think it is really healthy to be able to spend longer experiencing other specialities, hospitals and healthcare systems before having to } \\
\text { decide on your ultimate specialty. We should not be rushed.' [Female; General medicine] } \\
\text { 'The pressure to progress into specialty training and the subsequent rigidity of that training structure greatly hampers broad learning } \\
\text { and development of rounded doctors who progress into the specialty they will most enjoy and succeed in.' [Male; Emergency medicine] } \\
\text { 'I think there is too much pressure to promptly choose specialities following foundation. Personally although I knew that I wanted to } \\
\text { be an anaesthetist I would have liked to spend a couple of years gaining a broader experience before specialising, however, following } \\
\text { discussion with consultants it was felt that this would detract rather than add to my CV. I think that there should be greater availability } \\
\text { of broad pre-speciality training. This would also give junior doctors who are unsure of their career path time to decide.' [Female; } \\
\text { Anaesthetics] } \\
\text { 'While I'm very happy in my current specialty, and have a definite sub-specialty in mind, this is mostly by luck-I only definitely decided } \\
\text { to apply } 3 \text { months before the selection process due to uncertainty about what I wanted to do. More time before committing to a } \\
\text { specialty and more experience of medicine in general (similar to the old SHO posts) would have been much better.' [Male; Radiology] }\end{array}$ & 63 \\
\hline $\begin{array}{l}\text { Career choice is hampered by } \\
\text { inadequate career advice }\end{array}$ & $\begin{array}{l}\text { 'No formal careers advice: other than contacting senior doctors or the BMA there is nowhere to go to get advice.' [Female; Obstetrics \& } \\
\text { Gynaecology] } \\
\text { 'Regarding post-graduate career advice, I felt that plenty of advice was available if you asked for it, but it was all informal from friends, } \\
\text { colleagues etc. In my experience the level of formal career advice provided was extremely sparse.' [Female; Intensive care] } \\
\text { 'In terms of careers advice and support, it's difficult to know where to go if you have an alternative idea for your career development.' } \\
\text { [Female; Emergency Medicine] } \\
\text { 'More career advice from senior doctors and consultants would be appreciated. I would respect and be interested in their opinions on } \\
\text { my career. There is very limited place and space for this.' [Female; General medicine] } \\
\text { 'There needs to be greater training given to doctors who work as supervisors about the tools available to juniors for career } \\
\text { development; I accessed careers advice services post F2 as I had struggled to get this information during the foundation programme.' } \\
\text { [Female; Histopathology] } \\
\text { 'Career guidance is absent/non-existent and posts do not give adequate exposure to get a flavour of a specialty as a career choice.' } \\
\text { [Female; General medicine] }\end{array}$ & 42 \\
\hline $\begin{array}{l}\text { Some examples of comments } \\
\text { which made other points }\end{array}$ & $\begin{array}{l}\text { 'In relation to the question regarding timing of career choice, at the time I felt pressurised into making a decision without having had } \\
\text { the opportunity to experience some of the options I was considering. But looking back now, I am glad to be concentrating on the one } \\
\text { specialty I have chosen and not having to change jobs/specialty every } 4 \text { months.' [Female; Paediatrics] } \\
\text { 'I am currently working full time but intending to return to flexible training in the future. I feel that this is not as supported as it should } \\
\text { be.... It's hard to find out information and applying for it (based on previous application) is timing (sic) consuming and requires much } \\
\text { chasing.' [Female; Obstetrics and Gynaecology] } \\
\text { 'It has taken me nearly } 3 \text { years following starting work for me to have a good idea of future career plans and now it is very difficult } \\
\text { to change. We specialise too early and therefore do not have enough broad clinical experience in areas such as A\&E. ITU and acute } \\
\text { medicine and surgery. The skills and knowledge gained from these are not enough at an FY1 level-FY1 teaches patient management/ } \\
\text { organisation and time keeping but is not representative of future career choices. It is only as a CT1 that I have appreciated the clinical } \\
\text { experience these placements have given me and feel ready to enter a specialty.' [Female; specialty not given] }\end{array}$ & \\
\hline
\end{tabular}

${ }^{*} \mathrm{~A}$ total of 147 respondents provided comments. Some doctors covered more than one theme and we counted each theme.

can be challenging and may explain the concerns about early career decision-making by junior doctors. Policies about entry to specialty training should provide flexibility without unduly delaying the progression of those doctors who are certain, early on, about their preferred specialty.

For these doctors, a period of extra work experience clearly benefitted their clinical knowledge and confidence as practitioners.

Finally, our review of respondents' comments indicated that some doctors lack adequate career advice when choosing their long-term career specialty. Numerous organisations offer career advice and support for specialty choice decision-making for doctors in training in the UK (including the Foundation Programme board, the Deaneries, Royal Colleges, the British Medical Association and the NHS). Nevertheless, previous studies have reported dissatisfaction with the availability of career advice among junior and senior UK doctors ${ }^{1516}$ and have also revealed that very few doctors access career guidance when making choices. ${ }^{13}$ The results of this study echo these previous findings. Our work does not enable a robust assessment of whether doctors are unable or unwilling to access existing career counselling resources. However, examination of the free text comments provided by respondents suggests that some doctors are unaware and unable to easily access formal career guidance: in many cases, advice was obtained only via informal conversations with colleagues and superiors.

\section{Policy implications}

Studies have shown that career decisions can affect job satisfaction and morale among doctors in the UK. ${ }^{17}$ More broadly, research shows that time pressure and lack of experience can affect people's judgements ${ }^{18}$ and that decisions made in haste are often regretted. ${ }^{19}$ Consequently, our finding that a large proportion of UK-trained respondents feel they had to make a decision regarding their choice of long-term career specialty too 
soon after qualification should be of concern for medical workforce planners and healthcare organisations. This is particularly relevant given the recent rapid increase in the proportion of UK doctors who are choosing to interrupt their careers and not proceed directly on to specialist training: effectively choosing not to choose. ${ }^{8}$

Our findings highlight two priority actions that could be targeted by policy makers to improve the circumstances under which doctors are required to make important career decisions. First, identify methods and mechanisms to improve the availability and quality of career advice. At the very least, effective career guidance should be implemented from the start and throughout the Foundation Programme, if not earlier during the medical degree. ${ }^{16}$ Second, facilitate greater flexibility in training pathways. The medical profession in the UK and elsewhere has seen a recent shift towards increased flexibility in working patterns for doctors, driven largely by greater numbers of women in the profession. ${ }^{20}$ However, it is yet to embrace the idea of a non-traditional career trajectory. Many of the doctors who provided free-text comments in this study extolled the vocational benefits offered by an appropriately designed early career break.

This could be done by enabling alternative career paths to count towards training pathways and giving credit to doctors who seek out more diverse medical experiences before embarking on fixed paths. More formally, this could be greatly facilitated by the inclusion of a flexible 'F3' year in the Foundation Programme that would provide doctors with time to experience a greater variety of specialties or pursue wider experiences in their profession, prior to making life-long career decisions. While the majority of our survey respondents reported feeling rushed into choosing their career specialty, we acknowledge that a minority felt comfortable, or even content, with the timing of this decision (around one in five respondents 'Disagreed' with our statement). It is, therefore, critical that the adoption of a more flexible approach to medical training and career trajectories does not preclude a faster progression through training for those who choose it.

\section{Strengths and weakness of this study}

This is a large national survey of more than 5000 doctors in two cohorts of medical graduates from all UK universities undertaken in 2011 and 2015, during their third years of medical specialty training. Our surveys are conducted independently of any organisation that employs, trains or influences the doctors' careers. Confidentiality precludes substantiation of the veracity of respondents' responses, but respondents gained nothing by submitting erroneous information. We therefore believe that we get honest answers from respondents.

Nevertheless, there are certain limitations to our study. As with all voluntary surveys, our results may be susceptible to non-respondent bias. Considering this, we compared the responses of those who replied early (to the first or second survey mailing) with those who replied late (to one of the subsequent mailings and who would have been non-responders had we not persevered with follow-up mailings). There was no significant difference between these two groups in percentages that agreed that they had to choose a long-term career too soon after qualification (respectively, $61.5 \%$ cf. $60.0 \%$ ). Hence, non-respondent bias is not likely to be a major problem.

Many respondents chose not to comment and consequently the comments made are not necessarily representative of the views of the entire cohort. We used the free-text comments to gain insights into the motivations and reasons behind the doctors' responses and we present their content in a narrative not quantitative style. Those that commented may over-represent those who were dissatisfied with the circumstances of their career decisions. Similarly, we acknowledge that there may be other reasons than those we discuss here behind the doctors' responses to questions regarding the timing of their career decisions and career advice. We believe that the use of a priori coding of the free text was justified for this study because we wanted to expand on the answers to the quantitative question about timing. The final set of search terms we used was largely affirmative of the 'delayed decision' assumption, but our initial broad set of terms (eg, 'too late') did not result in comments which were outwith this model.

\section{CONCLUSION}

We have shown that a large proportion of UK-trained doctors feel rushed into making career decisions with potentially lifelong consequences. Our results suggest that much of the difficulty doctors face when choosing a career specialty arises because at the time of their decision, doctors lack sufficient medical experience (of clinical specialties and more broadly) and adequate career advice to make sound choices. Accordingly, we recommend that training organisations should enable greater flexibility

\section{Main messages}

- The majority of UK-trained respondents felt rushed into choosing their long-term career specialty, agreeing that they had to choose their career specialty too soon after qualification.

- Doctors who were uncertain about their choice of specialty or who were not employed in higher specialist training were more likely to report feeling rushed into choosing their longterm career.

- Some doctors found choosing a career specialty difficult because they lack sufficient medical experience (of clinical specialties and more broadly) and because career advice is inadequate.

\section{Current research questions}

- Increased provision of experience of which clinical specialties and skills would most benefit doctors prior to choosing their long-term career specialty?

- How could the current training programme for junior doctors be redesigned to increase the breadth of medical experience and expertise that doctors gain prior to specialist training?

- Why do seemingly few doctors access available career advice and guidance when making career decisions and how could access to such services be improved?

\section{What is already known on this subject}

- A declining proportion of UK junior doctors proceed directly to specialist training after their foundation years, with many taking career breaks.

- There is evidence that doctors are choosing to delay this important career decision. 
in training pathways and endeavour to further improve the existing career guidance for doctors.

Acknowledgements We thank Ritva Ellison for data management and Janet Justice and Alison Stockford for data entry. We are very grateful to all the doctors who participated in the surveys.

Contributors TWL and MG designed and conducted the surveys. SL performed the analysis and wrote the first draft of the paper. All authors contributed to further drafts and all approved the final version. All authors are guarantors.

Funding The report is based on independent research commissioned and funded by the NIHR Policy Research Programme (project number 016/0118, Cohort Studies of Doctors' Careers)

Disclaimer The views expressed in the publication are those of the author(s) and not necessarily those of the NHS, the NIHR, the Department of Health, 'arms' length bodies or other government departments.

Competing interests None declared.

Patient consent Not required.

Ethics approval National Research Ethics Service, following referral to the Brighton and Mid-Sussex Research Ethics Committee in its role as a multi-centre research ethics committee (ref 04/Q1907/48 amendment Am02 March 2015).

Provenance and peer review Not commissioned; externally peer reviewed.

Data sharing statement The authors may be able to make aggregated data from the study available on application.

Open access This is an open access article distributed in accordance with the Creative Commons Attribution Non Commercial (CC BY-NC 4.0) license, which permits others to distribute, remix, adapt, build upon this work non-commercially, and license their derivative works on different terms, provided the original work is properly cited, appropriate credit is given, any changes made indicated, and the use is non-commercial. See: http://creativecommons.org/licenses/by-nc/4.0

\section{REFERENCES}

1 Sievert M, Zwir I, Cloninger KM, et al. The influence of temperament and character profiles on specialty choice and well-being in medical residents. PeerJ 2016:4:23.
2 Scott A, Joyce CM. The future of medical careers. Med J Aust 2014;201:82-3.

3 Segal L, Bolton T. Issues facing the future health care workforce: the importance of demand modelling. Aust New Zealand Health Policy 2009;6:12.

4 Health Education England. Investing in people for health and healthcare: workforce plan for England, 2014.

5 Forde S, Green L. Rough guide to the foundation programme. 4 edn. London: Office UFP, 2015.

6 Bolton SC, Muzio D, Boyd-Quinn C. Making sense of modern medical careers: the case of the UK's National Health Service. Sociology 2011;45:682-99.

7 Agius SJ, Tack G, Murphy P, et al. Why do medical trainees take time out of their specialty training programmes? Br J Hosp Med 2014;75:584-9.

8 The UK Foundation Programme Office. Career destination report 2016. Career Destination Report, 2016.

9 Lambert TW, Goldacre MJ, Edwards C, et al. Career preferences of doctors who qualified in the United Kingdom in 1993 compared with those of doctors qualifying in 1974, 1977, 1980, and 1983. BMJ 1996;313:19-24.

10 Edwards C, Lambert TW, Goldacre MJ, et al. Early medical career choices and eventual careers. Med Educ 1997;31:237-42.

11 Department of Health. NHS next stage review: a high quality workforce. 2008. Available: http://www.dh.gov.uk/prod_consum_dh/groups/dh_digitalassets/@dh/@ en/documents/digitalasset/dh_085841.pdf [Accessed 30 Jan 2012].

12 General Medical Council. National training survey. London: General Medical Council, 2014.

13 Campbell N, Sabra A, Alderson L, et al. Choosing a specialty. BMJ 2009:b5237.

14 Betz NE. Self-concept theory in career development and counseling. Career Dev Q 1994;43:32-42.

15 Lambert TW, Goldacre MJ. Views of doctors in training on the importance and availability of career advice in UK medicine. Med Educ 2007;41:460-6.

16 Jackson C, Bal IJE, Harsh W. Informing choices: the need for career advice in medical training. Cambridge: National Institute for Careers Education and Counselling, 2003

17 Finlayson B. Counting the Smiles. London: The King's Fund, 2002.

18 Maule AJ, Svenson 0. Time pressure and stress in human judgment and decision making. Springer US, 2013.

19 Inbar Y, Botti S, Hanko K. Decision speed and choice regret: When haste feels like waste. J Exp Soc Psychol 2011;47:533-40.

20 Jones M. 'Mainstreaming' of less than full-time training. Anaesthesia 2015;70:641-4. 